\title{
Tuboenterocutaneous fistula following caesarean section
}

\author{
Manwar Ali Sheikh ${ }^{1}$, Jasmina Begum ${ }^{2}$, Gopal Balasubramanian ${ }^{1}$ \\ ${ }^{1}$ Department of Surgery, JIPMER, Dhanawantri Nagar, Puducherry-605006, India \\ ${ }^{2}$ Department of Obstetrics and Gynecology, Mahatma Gandhi Medical College and Research Institute, \\ Pilaiyarkuppam, Puducherry-607402, India
}

Received: 03 February 2014

Accepted: 16 February 2014

\section{*Correspondence:}

Dr. Manwar Ali Sheikh,

E-mail: alysmanwar@yahoo.co.in

C 2014 Sheikh MA et al. This is an open-access article distributed under the terms of the Creative Commons Attribution Non-Commercial License, which permits unrestricted non-commercial use, distribution, and reproduction in any medium, provided the original work is properly cited.

\begin{abstract}
Fistulous communication between fallopian tube, sigmoid colon and the skin after caesarean section is an unreported entity so far. Here we report a case of tuboenterocutaneous fistula which developed after wound complication following lower segment caesarean section (LSCS). Computed tomography (CT) was used to diagnose the case and laparotomy was done as definitive surgery.
\end{abstract}

Keywords: Tuboenterocutaneous fistula, Lower segment caesarean section (LSCS)

\section{INTRODUCTION}

Fistula following caesarean section is not very uncommon. Classical caesarean section practiced in the yester years were more prone to fistula, the incidence of which has come down due to practice of, lower segment caesarean section (LSCS). ${ }^{1}$ Fistula between the genital tract, bowel and skin results more commonly due to underlying co morbidities. These could range from tuberculosis, Crohn's disease, endometriosis to inadvertent retention of swabs (gossipyboma). Here we report an unusual case of tuboenterocutaneous fistula following lower segment caesarean section (LSCS).

\section{CASE REPORT}

A 20 years old lady, $\mathrm{P}_{1} \mathrm{~L}_{1}$, presented with history of fecopurulent discharge from her lower segment caesarean section (LSCS) pfannenstiel scar, which was done 8 months back. Patient developed surgical site infection after caesarean section which did not heal and gradually became fecopurulent. After unsuccessful treatment in one more hospital she finally presented in our outpatient department. No previous history of tuberculous, abdomen pain or distension, fever and abnormal white discharge per vagina was present. Her bowel and bladder functions were normal and she had not resumed her menstrual cycles after her child birth. On examination she appeared depressed, and her general condition was normal. On abdominal examination she had suprapubic transverse scar (pfannenstiel scar) with an opening on the left end of the scar with fecopurulent discharge. Rest of the abdomen was soft with no organomegaly. Per vaginal and per rectal examinations were normal. We proceeded with investigation of the patient. Ultrasonography and CECT of abdomen and pelvis was done apart from other routine investigations. Ultrasonography of abdomen and pelvis showed evidence of $4 \times 3 \mathrm{~cm}$ sized ill-defined mass formed between left side uterine cornu and bowel loops. CECT abdomen and pelvis gave a more clear picture of the fistulous tract which was of length of $7.6 \mathrm{~cm}$ arising from sigmoid colon with wall enhancement and communicating directly to the anterior abdomen skin layer in suprapubic region (Figure 1 and 2). Another tract of length $2.7 \mathrm{~cm}$ was seen arising from the above tract communicating to the endometrial cavity (Figure 3). Patient was taken up for exploratory laparotomy. Intraoperatively we found sigmoid colon, left uterine cornu, left side fallopian tube and omentum forming a mass, which was adherent to the parietal wall. About 10 
$\mathrm{ml}$ of pus was found on separating the omentum from the mass. Surprisingly the adhesions in the vicinity were very minimal. The whole mass was dismantled from the parieties, the sigmoid colon was dissected out from the uterine cornu, fistulous tract was excised, and left side partial salpingectomy was done. The diseased sigmoid colon was resected and anastomosis done. The abdomen was closed with a drain. Postoperative period was uneventful; she was discharged on post-operative day 7 and is on regular follow up. Histopathological study revealed, fistulous tract lined by granulation tissue with no specific inflammation, one edge of excised tissue showed muscular coat of intestine with columnar epithelium and the tract also showed columnar cells lined plical epithelium suggestive of epithelium of fallopian tube. There was no evidence of endometriosis or tuberculosis.

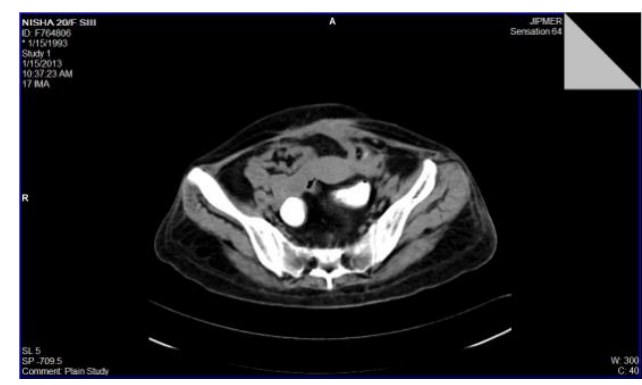

Figure 1: Plain CT of abdomen showing uterine cornu and bowel communicating through the parieties into the skin.

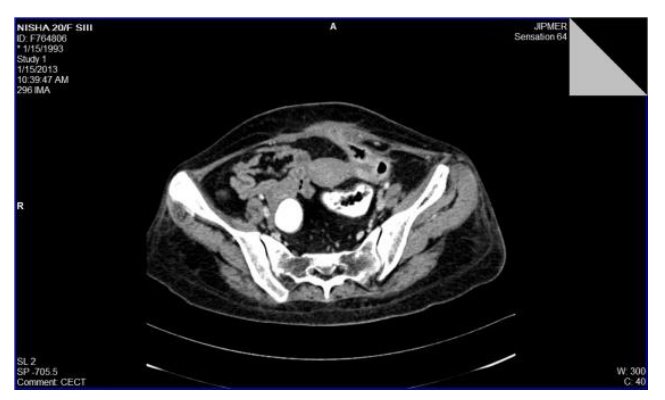

Figure 2: CECT of abdomen showing uterine cornu and sigmoid colon forming a mass along with the surrounding collection medial to the sigmoid colon suggestive of abscess.

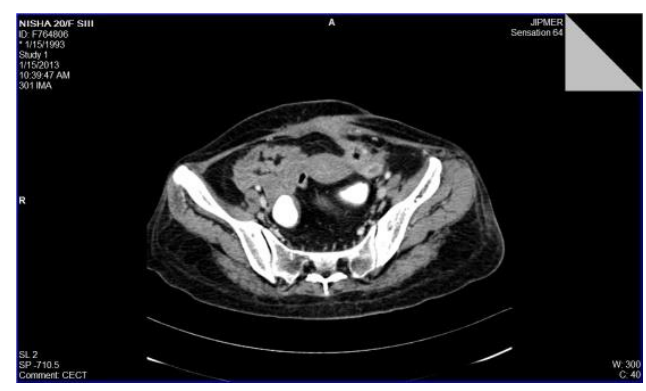

Figure 3: CECT of abdomen with the fistulous tract arising from the mass to the skin surface.

\section{DISCUSSION}

The communication between the fallopian tube and the gut is a very rare condition. This communication can result from obstetric, surgical and medical complications such as caesarean section, dilatation and curettage, inflammatory bowel disease, pelvic radiation, perforated appendicitis, diverticulitis, pelvic inflammatory disease, endometriosis and tuberculosis. ${ }^{2}$ Enterocutaneous fistula following caesarean section per-se is rare although a few cases of uterocutaneous fistula have also been reported in the literature. Two cases of uterocutaneous fistula following lower segment caesarean section (LSCS) has been reported with histopathology revealing tuberculosis and endometerosis. ${ }^{3,4}$ A case of tubocutaneous fistula resulting due to Crohn's disease has also been reported. ${ }^{5}$ Any communication between the bowels, fallopian tube upto the skin is unreported so far. In most of the cases infection was a complicating factor. In our case as well the factor responsible was most probably the pelvic collection which resulted in the abnormal fistulation. Injury to the tube, bowel with post-operative surgical site infection could be the most probable cause for fistulation. The primary investigation modalities for enterocutaneous, uterocutaneous, tuboenterocutaneous fistula are CT and MRI. They have the ability to demonstrate extraluminal disease, like associated abscess, tumors, and other coexisting diseases. The site and the fistulous tract are better delineated which helps in guiding the surgical procedure. $^{6}$ Traditional contrast investigation like hysterosalphingography is also helpful for fistula communicating genital tract and parieties. ${ }^{7}$ Diagnosis in our case was easily arrived at by contrast CT. Surgery remains the only corrective treatment for any fistula.

\section{ACKNOWLEDGEMENTS}

I would like to thank Professor Sarath Chandra Sistla and Professor D. Papa for their support and the Department of Radiology JIPMER.

Funding: No funding sources Conflict of interest: None declared

Ethical approval: Not required

\section{REFERENCES}

1. Desoouky DA. Uteroabdominal sinus following caesarean section. Am J Obstet Gynecol. 1980;137(1):147-8.

2. Rahimi A, Rasekhi AR. Tubosigmoid fistula secondary to perforated appendicitis. Arch Clin Exp Surg. 2013;2(2):132-5.

3. Dragoumis K, Mikos T, Zafrakas M, Assimakopoulos E, Stamatopoulos P, Bontis J. Endometriotic uterocutaneous fistula after caesarean section. Gynecol Obstet Invest. 2004;57(2):90-2.

4. Pant PR. Uterocutaneous fistula. Rare complication of caesarean section. NJOG. 2012;7(3):66-7. 
5. Choe SA, Lee HJ, Moon KY, Kim YB, Jean YT. A tubocutaneous fistula in a patient with Chro's disease after multiple laparotomies: a case report. $\mathrm{J}$ of Women's Med. 2008;1(2);188-9.

6. Perry J, Pickhart, Sanjeev B, Dennis M, Balfe. Acquired gastrointestinal fistula: classification, etiologies and imaging evaluation. Radiology. 2002;224:9-23.
7. McFarlane MEC, Plummer JM, Remy T, Christie L, Laws D, Richards H, Cherrie T, Edwardsr, Cowards C. Jejunouterine fistula: a case report. Gynecol Surg. 2008;5:173-5.

DOI: $10.5455 / 2320-1770 . i j r \operatorname{cog} 20140366$

Cite this article as: Sheikh MA, Begum J,

Balasubramanian G. Tuboenterocutaneous fistula

following caesarean section. Int J Reprod

Contracept Obstet Gynecol 2014;3:288-90. 